\title{
The importance of patient perspectives in pulmonary hypertension
}

\author{
Michael D. McGoon ${ }^{1}$, Pisana Ferrari ${ }^{2}$, lain Armstrong ${ }^{3}$, Migdalia Denis ${ }^{4}$, \\ Luke S. Howard ${ }^{5}$, Gabi Lowe ${ }^{6}$, Sanjay Mehta ${ }^{7}$, Noriko Murakami $^{8}$ and \\ Brad A. Wong ${ }^{9}$ \\ Number 13 in the series \\ "Proceedings of the 6th World Symposium on Pulmonary Hypertension" \\ Edited by N. Galiè, V.V. McLaughlin, L.J. Rubin and G. Simonneau
}

\begin{abstract}
Affiliations: ${ }^{1}$ Cardiovascular Diseases and Internal Medicine, Mayo Clinic, Rochester, MN, USA. ${ }^{2}$ Pulmonary Hypertension Association Europe, Vienna, Austria. ${ }^{3}$ Pulmonary Hypertension Association UK, Sheffield, UK. ${ }^{4}$ Sociedad Latina de Hipertensión Pulmonar, Venezuela. ${ }^{5}$ National Pulmonary Hypertension Service, Hammersmith Hospital, Imperial College Healthcare NHS Trust, London, UK. ${ }^{6}$ Jenna Lowe Trust, Republic of South Africa. ${ }^{7}$ London Health Sciences Centre, Division of Respirology, Dept of Medicine, Schulich School of Medicine, Western University and Pulmonary Hypertension Association Canada, London, ON, Canada. ${ }^{8}$ Pulmonary Hypertension Association Japan, Tokyo, Japan. ${ }^{9}$ Pulmonary Hypertension Association, Silver Spring, MD, USA.
\end{abstract}

Correspondence: Michael D. McGoon, Cardiovascular Diseases and Internal Medicine, Mayo Clinic, 200 1st Street SW, Rochester, MN 55905, USA. E-mail: mdmcgoondgmail.com

\section{@ERSpublications}

Analysis and discussion on the importance of patients' perspectives in pulmonary hypertension http://ow.ly/edOt30mgYoI

Cite this article as: McGoon MD, Ferrari P, Armstrong I, et al. The importance of patient perspectives in pulmonary hypertension. Eur Respir J 2019; 53: 1801919 [https://doi.org/10.1183/13993003.01919-2018].

ABSTRACT The assessment of objective measurement of cardiopulmonary status has helped us achieve better clinical outcomes for patients and develop new therapies through to the point of market access; however, patient surveys indicate that more can be done to improve holistic care and patient engagement. In this multidisciplinary review, we examine how clinical teams can acknowledge and embrace the individual patient's perspective, and thus improve the care for individual patients suffering from pulmonary hypertension by cultivating the importance and relevance of health-related quality of life in direct clinical care. At the individual level, patients should be provided with access to accredited specialist centres which provide a multidisciplinary approach where there is a culture focused on narrative medicine, quality of life, shared decision making and timely access to palliative care, and where there is participation in education. On a larger scale, we call for the development, expansion and promotion of patient associations to support patients and carers, lobby for access to best care and treatments, and provide input into the development of clinical trials and registries, focusing on the patients' perspective. 


\section{Introduction}

This article provides an overview of the role of the patient's perspective in understanding and managing pulmonary hypertension (PH). "Patient perspective" is the patient's experience of $\mathrm{PH}$ and its impact on him/her and caregivers, including symptomatic, intellectual, psychosocial, spiritual and goal-oriented dimensions of the disease and its treatment. Implicit in the concept of perspective is how it can be effectively communicated, understood and acted upon by others involved with the patient, including primary and subspecialty healthcare providers (HCPs), adjunctive professional providers (e.g. mental health and spiritual counsellors), family and social network, and health-related influencers (e.g. government, insurers and medical industry).

\section{Assessing the patient perspective \\ Surveys}

Surveys of pulmonary arterial hypertension (PAH) patients provide insights into patients' perceptions of impactful aspects of their disease [1-5]. A general conclusion among surveys is that although the clinical definition of the severity of disease appropriately includes symptomatology, exercise capacity, biomarkers, invasive and non-invasive haemodynamic measurements, and survival, these parameters do not capture the extensive realm of physical, emotional and psychosocial issues which affect patients and their caregivers (figure 1).

\section{Health-related quality of life measures}

Generic and disease-specific measures of "health-related quality of life" (HRQoL) have been evaluated in $\mathrm{PH}$ patients (table 1) [6-18]; physical/functional, emotional and social aspects of HRQoL are negatively impacted by $\mathrm{PH}$ [19-21]. PH therapies produce a variable benefit in HRQoL (table 2) [22-42]. Some measures of HRQoL may also correlate with survival prognosis [43]. Importantly, medications directed towards concomitant health issues (e.g. depression, anxiety and sleep disorders) [44] or nonpharmacological therapies (e.g. exercise programmes, psychosocial counselling, health coaching and access to nurse specialists or palliative care strategies) [45-51] may improve HRQoL.

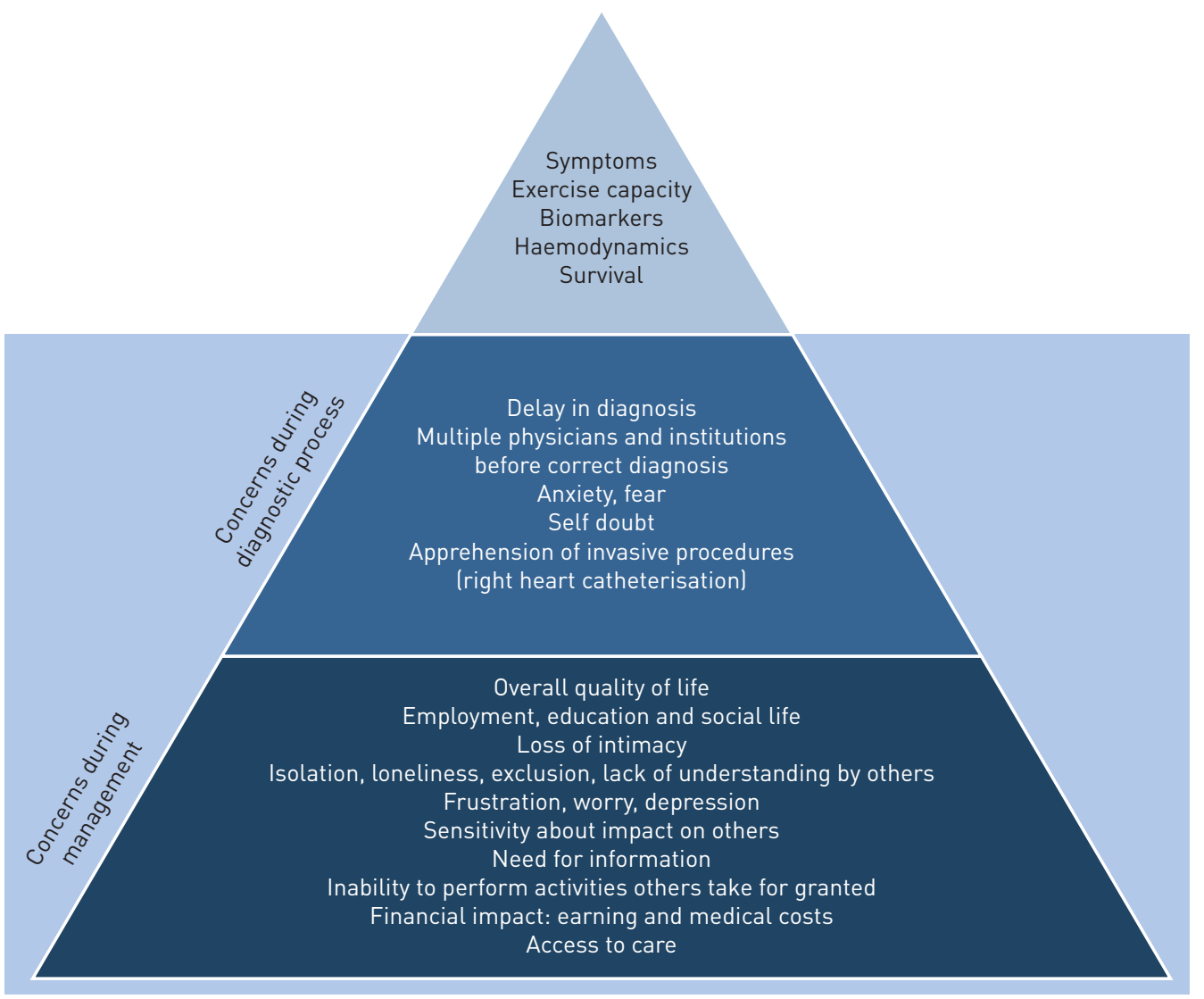

FIGURE 1 Surveys of patients and caregivers suggest that traditional parameters of pulmonary hypertension severity may be the "tip of the iceberg" when the broader range of patient concerns is considered. 


\begin{tabular}{|c|c|c|c|}
\hline Measure [ref.] & Domains & Items $\mathbf{n}$ & Recall period \\
\hline \multicolumn{4}{|l|}{ Generic } \\
\hline SF-36 [9] & $\begin{array}{l}\text { Physical functioning, role limitations physical, bodily } \\
\text { pain, general health, vitality, social functioning, role } \\
\text { limitations emotional, mental health }\end{array}$ & 36 & $\begin{array}{l}\text { Now to past } \\
4 \text { weeks }\end{array}$ \\
\hline$E Q-5 D[10]$ & $\begin{array}{l}\text { Health state description: mobility, self-care, usual } \\
\text { activities, pain/discomfort, anxiety/depression; overall } \\
\text { health status (visual analogue scale) }\end{array}$ & 51 & Today \\
\hline NHP [11] & $\begin{array}{c}\text { Mobility, pain, social isolation emotional reactions, } \\
\text { energy level, sleep }\end{array}$ & 38 & At the moment \\
\hline HADS [12] & Anxiety, depression & 14 & At the moment \\
\hline \multicolumn{4}{|l|}{ PAH specific } \\
\hline CAMPHOR [13] & $\begin{array}{l}\text { Overall symptoms (energy, breathlessness, mood), } \\
\text { functioning, quality of life }\end{array}$ & 65 & Today \\
\hline MLHFQ [14] & Physical, emotional & 21 & 4 weeks \\
\hline LPH [15] & Physical, emotional & 21 & 1 week \\
\hline CHFQ [16] & Dyspnoea, fatigue, emotional function, mastery & 20 & 2 weeks \\
\hline emPHasis-10 [17] & Unidimensional & 10 & At the moment \\
\hline PAH-SYMPACT [18] & $\begin{array}{l}\text { Respiratory symptoms, tiredness, cardiovascular } \\
\text { symptoms, other symptoms, physical activities, daily } \\
\text { activities, social impact, cognition, emotional impact }\end{array}$ & 41 & $\begin{array}{l}24 \mathrm{~h} \text { for } \\
\text { symptoms; } \\
7 \text { days for imacts }\end{array}$ \\
\hline
\end{tabular}

SF-36: Medical Outcomes Study 36-item short form; EQ-5D: EuroQol Group 5-Dimension Self-Report Questionnaire; NHP: Nottingham Health Profile; HADS: Hospital Anxiety and Depression Scale; CAMPHOR: Cambridge Pulmonary Hypertension Outcome Review; MLHFQ: Minnesota Living with Heart Failure Questionnaire; LPH: Living with Pulmonary Hypertension questionnaire; CHFQ: Chronic Heart Failure Questionnaire; emPHasis-10: 10-question survey proposed by the Pulmonary Hypertension Association UK. Information based on and expanded from [6].

\section{Current status}

"Patient perspective" can be viewed through two different but related lenses: 1) the individual's perspective as it relates to each patient's individual situation and 2) the aggregate perspective of the $\mathrm{PH}$ population, i.e. a perspective of common denominators despite unique individual variations.

\section{Individual patient perspective}

Recognition of the importance of the individual patient's perspective regarding their experience of $\mathrm{PH}$ is exemplified by the evolving patient/HCP clinical interaction. The traditional model of this relationship (exploration of symptoms and physical findings with tests culminating in a diagnosis and treatment recommendations) has been the subject of algorithms and guidelines [45, 52-54]. The management of $\mathrm{PH}$ is increasingly complex, including medications administered by different routes with unpredictable degrees of beneficial and adverse effects, options for invasive or surgical interventions, differences in practice settings and access to treatment from centres to community practices, decreased time spent with patients, and considerations of cost and follow-up. Increasing recognition of this complexity of $\mathrm{PH}$ and its treatment, and of the importance of the individual patient's perspective, including their understanding of $\mathrm{PH}$ and appreciation of the burden of their illness and impact on their HRQoL, requires a bidirectional exchange of opinions and objectives between patients and HCPs, in order to promote integration of the patient perspective into the patient/HCP relationship. This patient-centred collaborative care approach is finding expression in concepts such as narrative medicine, shared decision making and palliative care, leading to greater patient engagement, involvement and empowerment in management of their illness [55].

Narrative medicine

A key feature of patient-centred medicine in chronic conditions such as $\mathrm{PH}$ is that the patient presents with a spectrum of symptoms and associated psychological responses which occur within a sociological and cognitive framework unique to that patient, and which contribute to the patient's fears, coping mechanisms and goals. Treatment focused exclusively on the underlying disease often fails to address the ripples of impact provoked by $\mathrm{PH}$ which may become the main source of concern to the patient. The ability of HCPs to "acknowledge, absorb, interpret, and act on the stories and plights of others" has been referred to as narrative competence, the foundation of narrative medicine [56]. The intention of narrative 
TABLE 2 Effect of pulmonary arterial hypertension (PAH) medications on health-related quality of life (HRQoL) measures

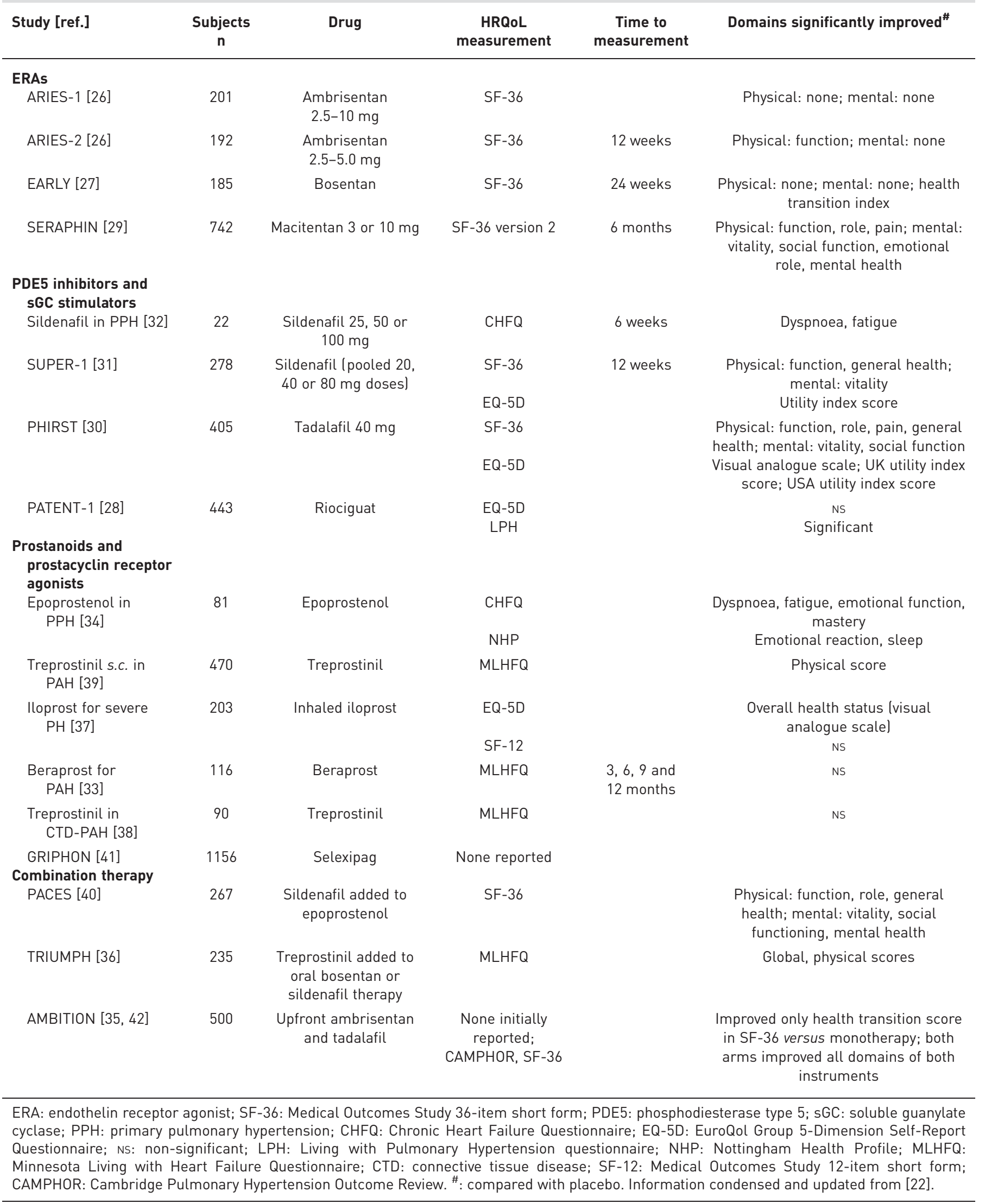


medicine is to adopt a broad perspective in terms of appreciating the entire spectrum of the patient's presentation and also by enlisting elements of other disciplines (such as the humanities and literature) to best understand that spectrum $[57,58]$. The contribution of narrative knowledge is to provide a balance or context for the scientific dimension of medicine $[59,60]$. Narrative medicine addresses the issue of how a unique individual under unique circumstances can be uniquely helped, whereas scientific medicine asks how the features of patients' presentations make them statistically similar or dissimilar to a demographic which responds in a given way to a particular management strategy.

In a practical sense, patients should be able to discuss with HCPs not only symptoms, but their experience of their individual illness in terms of functional burden and psychosocial impact, as well as their objectives of treatment. HCPs should encourage patients to express their perspective, be receptive to and attempt to comprehend and incorporate their views into management. An interaction of this type is crucial since the HCPs' goals for $\mathrm{PH}$ therapy tend towards achieving symptomatic and functional improvement, delaying worsening of disease, and extending life expectancy. Patients may emphasise quality of life, capability for coping with daily demands and minimising the burdens of complex therapies [61]. This mutually respectful bidirectional interaction would establish common ground for the process of shared decision making.

\section{Shared decision making}

The definition of shared decision making is succinctly stated in commonsense terminology: "a conversation between the clinician [and others, such as pastoral counsellor and social worker] and the patient in which they figure out together what to do to address the patient's situation" [62]. This concept incorporates components that are "iterative and interactive steps in a conversational dance", which include: clarifying the patient's situation; identifying the aspect of the situation that requires action; recognising that more than one way of addressing the situation exists; discussing the pros and cons of the available approaches with the patient and caregivers; and gaining understanding of what the patient values about these options, and why [62].

For the patient perspective to be valid and relevant, it must be informed by an accurate comprehension by the patient of the facts of the situation. In some medical disciplines, decision aid tools have been developed to facilitate the patient's understanding of the clinical context and potential outcomes of alternative treatment strategies, including those which are probabilistic in nature. Decision aids promote the patient's knowledge, estimation of treatment risk and engagement in the discussion. However, there has not yet been a demonstrable benefit in terms of outcome [62]. Standardised decision aids have not been developed for PH management.

\section{Palliative care}

Palliative care was traditionally a change in the focus of care at the end of life away from therapies intended to cure or slow the progression of disease, to management of physical symptoms (e.g. pain) and emotional distress. Palliative care is currently better understood as an interdisciplinary approach to promoting quality of life and reducing suffering at any stage of chronic disease [63]. Palliative care has been defined as "patient and family-centered care that optimizes quality of life by anticipating, preventing, and treating suffering. Palliative care throughout the continuum of illness involves addressing physical, intellectual, emotional, social, and spiritual needs and to facilitate patient autonomy, access to information, and choice" [64].

In a survey of $774 \mathrm{PAH}$ patients, 276 analysable responses revealed that awareness of and access to palliative care resources were low despite marked impairment of HRQoL, physical and emotional wellbeing, social activity, and pain control [49]. This degree of diminished HRQoL is consistent with that found in other studies [20, 49, 65-69]. Since PH-targeted therapies do not usually alleviate all physical symptoms or necessarily improve patients' psychosocial function, a role for integrating palliative care techniques and expertise early to optimise HRQoL has been advocated [70].

Obstacles to expanding the use of palliative care in $\mathrm{PH}$ patients are lack of awareness of its purpose (e.g. symptom management and psychological wellbeing), inadequate local medical payer coverage, misunderstanding palliative care as synonymous with hospice care and implies "giving up" or being resigned to an imminent death, and not understanding that $\mathrm{PH}$-targeted medications can continue within a palliative care strategy [63]. Therapies for $\mathrm{PH}$ have side-effects which may negatively impact HRQoL despite achieving benefits in terms of haemodynamics and some symptoms. Thus, strategies to focus on HRQoL during otherwise beneficial treatment arguably become even more imperative.

\section{PAH population perspective}

Patients and caregivers need support from others, which can take many different forms: awareness that others are confronting similar struggles, sharing experiences and information, suggesting solutions to 
shared challenges, attending formal educational events, participating in collaborative efforts to advance care, and unifying around shared needs and goals to raise awareness.

\section{Patient associations}

Organisations have been created to facilitate the expression of the $\mathrm{PH}$ population perspective and to aid in dealing with the needs of $\mathrm{PH}$ patient communities worldwide (table 3).

\section{Support groups}

Support groups are smaller local patient networks with less infrastructure and expense which provide informal interactions to offer empathetic sharing of experiences and education. Support groups may be independent or promoted by medical institutions or pharmaceutical companies, and may receive logistical or financial assistance from national patient associations. Such local/regional support groups exist in many countries especially in North America (e.g. more than 240 identified by the Pulmonary Hypertension Association (PHA) in the USA), but also in a number of European, Latin American, Asian and African nations.

\section{Education/awareness}

Acquiring information about $\mathrm{PH}$ is an essential coping mechanism for many patients. In addition, the perception that others lack awareness and knowledge about their disease is distressing. Insights provided to patients in subspecialty clinics by dedicated staff helps address these needs [50, 71], but public dissemination of information also is central to patient organisations' mission. A pivotal component of this effort has been to increase awareness of $\mathrm{PH}$ both in HCPs and the general population in order to improve the timeliness and accuracy of PH diagnosis in patients presenting with suggestive symptoms (e.g. the "Early Diagnosis" campaign of the US PHA), catalysed by observations that there is a significant interval between symptom onset and definitive diagnosis $[4,5,72]$.

The annual World Pulmonary Hypertension Day was first held on May 5, 2012 in Madrid, Spain to raise global awareness and this was adopted by PHA Europe (http://worldphday.org). The World Pulmonary Hypertension Day has gained increasing momentum, with 86 global partner organisations involved in an international awareness campaign in 2018. Through its involvement of national political and health authorities, academia, HCPs, and celebrities, World Pulmonary Hypertension Day has generated media interest and awareness across the world.

Evaluation of patients at referral centres frequently identifies aspects of pre-referral management that do not align with best practices and guidelines [73]. Concerned physicians and patients in the PH community re-emphasised the need for professional education, including periodic international symposia (e.g. the World Symposia on Pulmonary Hypertension (WSPH) [74] and the European Society of Cardiology (ESC)/European Respiratory Society (ERS) guidelines for PH [45], culminating in publications of state-of-the-art knowledge summaries, management guidelines and algorithms), web-based educational programmes, on-site preceptorships and $\mathrm{PH}$-focused publications.

\section{Access to healthcare/coverage}

Disparity in healthcare access is a worldwide issue which patient organisations address on behalf of their constituencies. A major concern of patients, their families and primary HCPs is where the patient should be most effectively managed. This concern embodies many elements: how can qualified experts and well-resourced medical facilities be identified; how can geographical and financial constraints be navigated; by whom are complex treatment strategies best prescribed, managed and followed; and what is the best approach to medical emergencies? The answers are largely dependent on the geographical location and nationality of the patient.

In the USA, under the aegis of the PHA, the PH Care Centers (PHCC; https://phassociation.org/ phcarecenters) programme of site accreditation was developed to identify facilities which are staffed and equipped to deliver patient management that meets expert consensus for best practices.

The European Reference Networks (ERNs; https://ec.europa.eu/health/ern_en) for rare diseases, launched in 2017, introduced a European Union (EU) accreditation system for centres of expertise for rare diseases to whom referrals can be made for "virtual" consults. The EU initiative is intended to facilitate cross-border sharing of knowledge, experience, medical research, teaching, training and resources. Patients are closely involved and each ERN has a Patient Advisory Group (ePAG) which advises on strategy, policy and organisational processes. PHA Europe has three representatives on ERN Lung.

Latin American and Asian countries also confront difficulties with early diagnosis and access to treatment for $\mathrm{PH}$ patients due to lack of knowledge and insufficient legal frameworks to protect the right to good 
TABLE 3 Representative pulmonary hypertension $(\mathrm{PH})$-focused patient organisations ${ }^{\#}$

\section{Organisation (website}

Pulmonary Hypertension

Association

(https://phassociation.org)

Pulmonary Hypertension Association Canada

(www.phacanada.ca)

Pulmonary Hypertension Association Japan [www.pha-japan.ne.jp]

Pulmonary Hypertension Association UK

(www.phauk.org)

\section{Region; beginning}

Canada; 1999 as Pulmonary Hypertension Society of Canada, renamed PHA Canada in 2008

Japan; 1999

UK; 2000

Pulmonary Hypertension Association Europe (www.phaeurope.org

Latin Society of Pulmonary Hypertension (Sociedad Latina de Hipertensión

Pulmonar)

(www.sociedadlatinahp.org)
All PH patients and their caregivers,

physicians and allied healthcare professionals; engagement: >1000 (note no formal membershipl

\section{PAH and CTEPH patient, caregivers} membership: $>200$

PAH and CTEPH patients, caregivers, hysicians and allied health professionals, researchers; membership: $>4000$ patient and $>200 \mathrm{HCPs}$ American patient associations in 16 countries

Umbrella organisation for 40 patien associations in 33 countries
Constituency

PAH and CTEPH patients, caregivers, physicians and allied health professionals,

researchers; membership: >16000

\section{Mission}

To extend and improve the lives of those affected by $\mathrm{PH}$

To empower the Canadian PH community through awareness, advocacy, education, research and patient support"

"Promotion of social awareness and understanding about $\mathrm{PH}^{\prime \prime}$

To advance the education and awareness of the general public and medical

professionals of the condition known as $\mathrm{PH}$ : the relief of need of sufferers of $\mathrm{PH}_{2}$ their families and carers through the provision of financial assistance towards, but not exclusively, respite care, travel grants and equipment grants at the discretion of the executive committee, as and when resources allow

"Promotion of social awareness and understanding about $\mathrm{PH}^{\prime \prime}$

"To raise awareness about $\mathrm{PH}$ throughout Latin America"

\section{Major activities}

Research funding support; advocacy; patie support and education, medical education and public awareness and education; PH

care centre accreditation

Patient/caregiver support and education: advocacy; medical education; public awareness and education; research funding support

Advocacy; patient support and education, public awareness; promoting early diagnosis and access to new drugs

Patient and family support, high-quality online/printed support materials, support and advocacy for all patients with all forms of $\mathrm{PH}$, increasing disease awareness within all areas of healthcare and general public; reduce the time to diagnosis for $\mathrm{PH}$; improve the health wellbeing and quality of life of patients with $\mathrm{PH}$ and their kinship; ensure equity of access in the UK to evidence-based $\mathrm{PH}$ treatments for all; reduce the financial hardship incurred by living with $\mathrm{PH}$

Improve access to expert care, improve awareness and screening, encourage clinical research and innovation, empower patient groups, ensure the availability of psychosocial support

Promoting optimal level of care for $\mathrm{PAH}$ patients, availability of quality treatments, research on new drugs and therapies, awareness and public policies; umbrella organisation supporting regional patient organisations; awareness campaigns include: "Labios Azules" ("Blue Lips") (2011): "Sin Aliento" ("Short of Breath") (2012); "Quedate sin Aliento" ("Stay Breathless") (2014) and "Un Aliento para Vencer" ("Breathe to Win") (2016) 


\begin{tabular}{|c|c|c|c|c|}
\hline Organisation (website) & Region; beginning & Constituency & Mission & Major activities \\
\hline $\begin{array}{l}\text { Pulmonary Hypertension } \\
\text { Association of Australia } \\
\text { (www.phaaustralia.com) }\end{array}$ & Australia; 2005 & $\begin{array}{l}\text { All categories of PH patients, caregivers, } \\
\text { family and supporters, pre- and } \\
\text { post-transplant patients; HCPs are } \\
\text { non-participant members trying to } \\
\text { understand the patient/family side of the } \\
\text { disease; membership }>7000\end{array}$ & $\begin{array}{l}\text { "To provide hope, support and education, } \\
\text { and to promote awareness and to } \\
\text { advocate for the PH community" }\end{array}$ & $\begin{array}{l}\text { Administered by volunteers for } 18 \text { years (no } \\
\text { paid staff); patient, caregiver and family } \\
\text { education; public awareness and education } \\
\text { through website and several social media } \\
\text { platforms; advocate for the PH community; } \\
\text { bereavement support; immediate phone } \\
\text { support for those in a PH-related crisis; } \\
\text { immediate online support through their } \\
\text { secure Facebook support group; work } \\
\text { closely with Australian specialists through } \\
\text { the Pulmonary Hypertension Society } \\
\text { of Australia and New Zealand } \\
\text { (www.phsanz.org) to ensure best outcome } \\
\text { for patients }\end{array}$ \\
\hline $\begin{array}{l}\text { iSEEKPH Hope Center } \\
\text { (www.iseek.org.cn) }\end{array}$ & China; 2011 & $\begin{array}{l}\text { Patients, caregivers, physicians, medical } \\
\text { professionals, researchers; membership: } \\
\qquad>5000\end{array}$ & $\begin{array}{l}\text { "To advocate for patients' equal rights and } \\
\text { improve their quality of life" }\end{array}$ & $\begin{array}{l}\text { Advocacy; patient education and support; } \\
\text { public awareness; education; research }\end{array}$ \\
\hline
\end{tabular}


healthcare by World Health Organization criteria. Scarcity of referral centres, inconsistency among health systems, wide distribution of patients, geographical barriers, economic disparity and limited accessibility to medical records have made it difficult to generate awareness of $\mathrm{PH}$.

\section{Advocacy and empowerment}

Patient-centred organisations acknowledge patients' needs within a supportive environment and provide opportunities for patients and caregivers to advocate for themselves by being proactive in defining their situations, proposing solutions, participating in political activity to promote those solutions, being engaged in their own self-care and counselling each other [55]. Patients' understanding of their illness and engagement in the care process appears to contribute to improved coping ability [71] and outcomes [75, 76] in a variety of chronic diseases. Patient associations and individual patients in many parts of the world are active advocates for better access to treatment, organ transplant and greater attention to quality of life.

PHA Europe has been successful in involving members of the European Parliament, top EU officials, members of the ESC and ERS, and representatives of influential public health European non-governmental organisation in PH-related issues, including for two European Parliament meetings (2012 and 2016). PHA Europe is also active in the context of larger European organisations, and gives support and strategic advice to national advocacy activities.

Lacking a national single-payer system, the US PHA undertakes simultaneous efforts to educate policy makers at both the federal and state levels, and inform and educate federal and state regulatory agencies (e.g. Centers for Medicare \& Medicaid Services and the US Food and Drug Administration (FDA), and state health and insurance agencies) and commercial payers. The US PHA uses a combination of advocacy staff, volunteer PH patients and caregivers, and coalitions of patient organisations with similar advocacy goals to influence policy makers.

The Latin Society of Pulmonary Hypertension (Sociedad Latina de Hipertensión Pulmonar (SLHP)) has supported improved living conditions of patients. One result of this is the Framework Law approved by the Health Commission of the Latin Parliament in 2015 and by other legislative forums to promote national laws that protect the Human Right to Health. This law regulates the healthcare for people with rare diseases in Latin America. However, the diversity, complexity, fracture and corruption of the health systems make it difficult to achieve a direct impact.

Role in research/registries

Patients have had a vital role in PAH-related clinical trials and registries, almost exclusively as study subjects. An early manifestation of the relevance of the patient perspective in research is the concept of patient-reported outcome (PRO) as a meaningful measurement of treatment effect of investigational drugs. In 2009, the US FDA stated that "A PRO is any report of the status of a patient's health condition that comes directly from the patient, without interpretation of the patient's response by a clinician or anyone else" [77]. The 4th and 5th WSPH, in 2008 and 2013, respectively, advocated that PROs be included as a secondary end-point in clinical drug studies [78, 79]. Patient input is needed to understand their perspective and experience so that PROs can be developed as relevant end-points in clinical trials [80]. The US FDA launched the Patient-Focused Drug Development initiative to assess and integrate patient perspectives into the early phases of drug development in a range of diseases [81]. A meeting involving PAH patients and representatives was held in 2014, and emphasised the impact of PAH on the individual patient's life beyond the physical burden of symptoms, including loss of independence, inability to perform routine daily activities and fully participate in relationships with significant others and children, embarrassment, fear of being alone, and impact of treatment side-effects on HRQoL [82]. This initiative represents an important step in incorporating patient perspective and engagement at an early stage of clinical trial design.

\section{Future directions}

In order to advance the role of patients, both as individuals and as a demographic group, to a position of empowerment and engagement in all aspects of their PAH experience with the goal of enhancing overall wellbeing [55], we suggest several areas in which to focus future attention (table 4). The common denominator of these suggestions is to cultivate the importance of HRQoL in the care PH patients.

\section{Clinical management}

Promote access to optimal management

Optimal care must be multidimensional to address the physical, psychological, social and informational needs of patients and caregivers, alongside their clinical needs. This approach is suggested by the latest ESC/ERS clinical guidelines: "[expert] Referral centres are recommended to provide care by an 
TABLE 4 Cultivate the importance of health-related quality of life (HRQoL) in the care of those affected by pulmonary hypertension $(\mathrm{PH})$

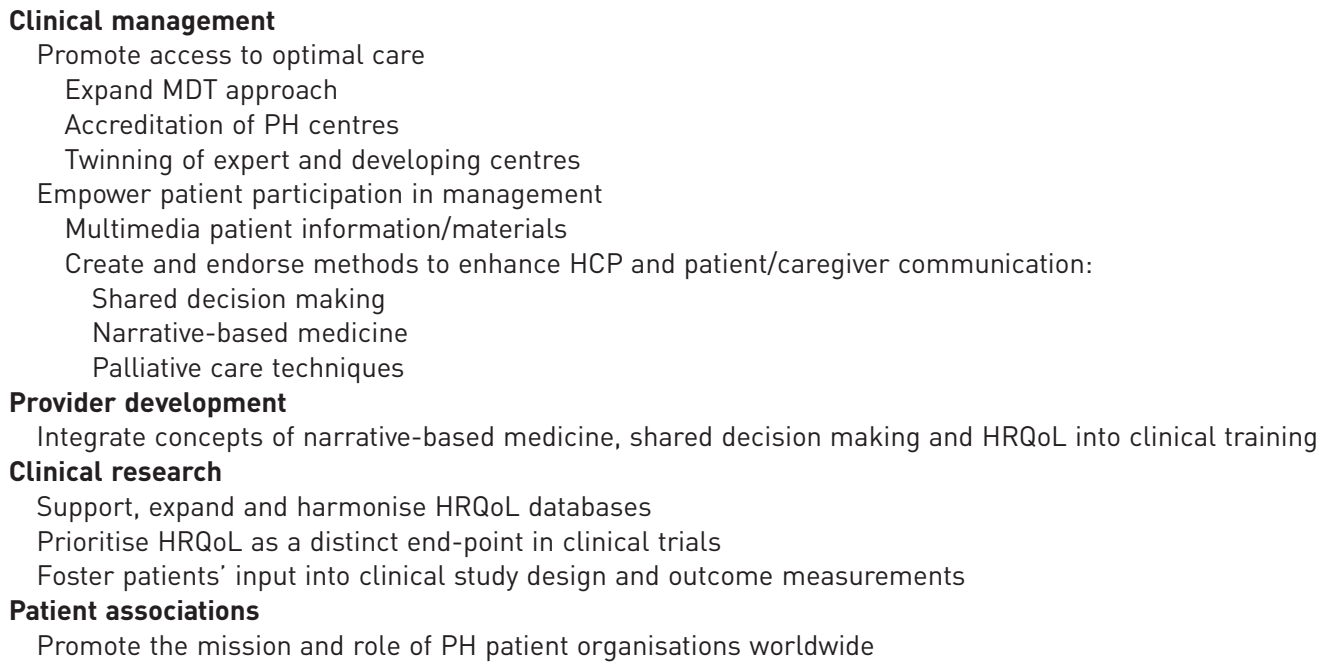

MDT: multidisciplinary team; HCP: healthcare provider.

interprofessional team ..." [45]. Nevertheless, guidelines are largely silent about the desirability of patient/ HCP bidirectional interactions that address patients' need for emotional support conducted by a collaborative team at a "tempo" which permits the patients to understand the HCP's information and to convey their perspectives, concerns and goals. Future guidelines should point out that HRQoL objectives require a culture of shared decision making and narrative competence to support patient and caregiver emotional resilience. This should include access to focused psychological management, social work, palliative care, spiritual counselling and physical therapy (figure 2).

Optimal care must be accessible to the patient. Mechanisms, such as ERNs and the PHCC, to evaluate and identify sites able to provide clinical management consistent with consensus guidelines are important steps. The next challenge is to promote restriction of care to such centres once sufficient numbers have been identified to serve the $\mathrm{PH}$ population. This is most likely to be achieved in systems with a single payer/commissioner, usually state provided.

In Latin America and in developing countries, future advances are particularly challenging because of the barriers noted earlier. A primary objective of patient organisations both in Latin America and worldwide will be to overcome these barriers and advocate for social, political and legal measures to procure accessible healthcare for $\mathrm{PH}$ patients. "Twinning relationships" between individual centres of expertise and centres seeking consultative input could be a means of promoting optimal care in needy regions. The regional disparity of care available to $\mathrm{PH}$ patients mandates that governments, insurers, the pharmaceutical industry, and patient and professional organisations promote global accessibility and affordable treatment for all $\mathrm{PH}$ patients. For a compelling narrative regarding the need for globalisation of $\mathrm{PH}$ care, please watch the Jenna Lowe Trust video at: https://phassociation.us13.list-manage.com/track/click? $\mathrm{u}=\mathrm{acd} 152 \mathrm{c} 7 \mathrm{c} 169 \mathrm{~b} 59 \mathrm{aaec} 993284 \& \mathrm{di}=4874 \mathrm{e} 4 \mathrm{af3a} \& \mathrm{e}=99080 \mathrm{~b} 0 \mathrm{e} 01$.

Empower patients' participation in their management

PH patients and HCPs collaboratively make decisions which have a major impact and require an understanding by all parties of the components and priorities involved in achieving an appropriate course of action. To achieve the necessary mutual understanding requires a complexity, duration and frequency of interaction that poses a challenge within the time constraints of medical practices. The process may be facilitated by incorporating formal principles of shared decision making, including the use of decision aid tools. A synthesis of the qualitative precepts of narrative medicine and the implementation of more quantitative HRQoL instruments in clinical practice might also enhance the physician's awareness of the patient's needs and systematically reflect aspects of illness that are not otherwise measured.

Patient associations frequently offer educational materials which complement the role of the HCP by providing information about the disease, treatment options and day-to-day issues in living with $\mathrm{PH}$. Since 2015, over 200 resources in 24 languages have been collected in the "PH Library" (www.ourphlibrary.com), 


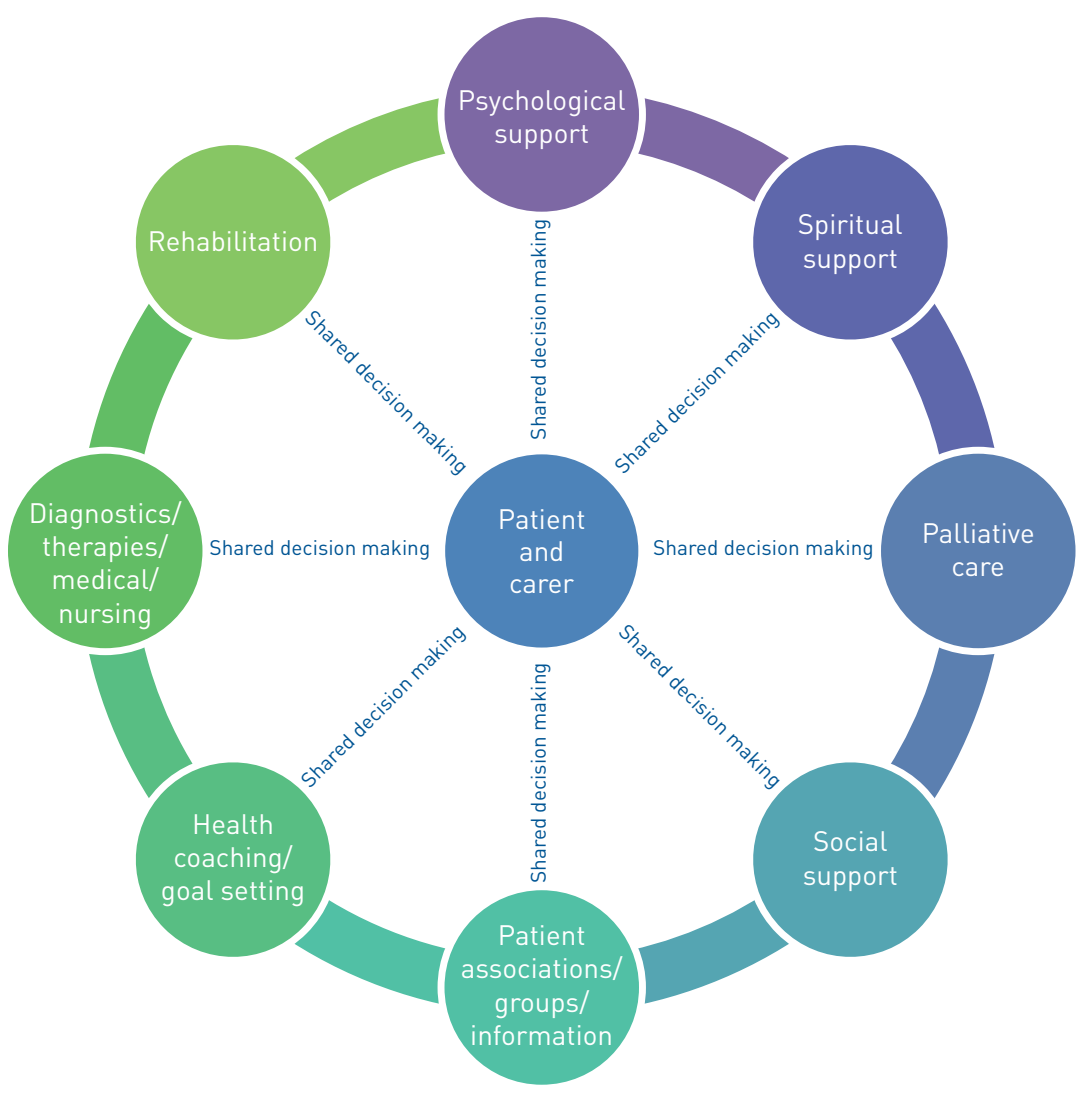

FIGURE 2 Representation of components of a multidimensional approach to care of the pulmonary hypertension patient.

an online joint project of PHA in the USA and PHA Europe, which should be continued and expanded. An additional role that patient organisations and support groups might play is to help patients develop narrative medicine knowledge and skills so they can be more effective during their limited time with HCPs.

\section{Role and timing of palliative care}

The assimilation of palliative care principles into the $\mathrm{PH}$ management strategy at an earlier phase of disease should be encouraged to promote all means of improving HRQoL by pain management, symptomatic improvement of dyspnoea, addressing psychological issues and sleep disturbances, and assisting in end-of-life concerns. Equating the term "palliative care", which is currently burdened with the notion of "end-of-life" care, with "holistic" or "quality-of-life" care will be an important strategy for reorienting perceptions about this discipline.

\section{Provider development}

Integrate concepts of patients' perspectives into medical education

Medical education has recognised the importance of the patient perspective to a degree, incorporating concepts of shared decision making, narrative-based medicine and HRQoL into educational curricula. Narrative medicine can potentially increase efficiency and bring economic benefits to healthcare systems. A closer and more collaborative patient-doctor relationship can improve treatment compliance and satisfaction, and reduce unnecessary tests and medicolegal disputes.

It is important to further integrate these concepts into all clinical disciplines, including $\mathrm{PH}$ management, at all levels of medical education from medical school to continuing medical education of all HCPs.

\section{Clinical research}

Support, expand and harmonise HRQoL databases

Surveys of patient perspectives are an important source of information by which HCPs can orient themselves to their patients' multiple and complex needs. Since perspectives may vary as the treatment milieu changes over time, it will be important to periodically reassess using updated survey instruments. 
Information derived from patient surveys can differ by geographical location. This suggests that the use of surveys in other regions of the world would be informative in terms of comparisons and would also provide new insights into the attitudes of previously unexamined populations, including those in Latin America, the Middle East, Africa and Asia.

Surveys of patient perceptions should be integrated with traditional clinical database registries Incorporation of these variables into a single or cross-linked case report form would potentially simplify (unify) data collection. Ultimately data analyses might better determine whether treatment strategies and traditional outcome measures (e.g. hospitalisation and survival) correlate with HRQoL. It is likely that these analyses would be hypothesis generating and lead to further formal study.

It would be useful if registries and/or patient surveys were designed to prospectively harmonise data variables in such a way that global analyses could be performed without resorting to post hoc statistical adjustment.

Incorporate patients' perspectives early into clinical study design and outcome measurements Based on information gleaned from surveys, including patients in the clinical trial design process may increase the importance of "overall wellbeing" as a central objective of medical care and potentially as a clinical trial outcome on an equal footing with more traditional end-points. HRQoL could be included as an end-point by itself or as part of a multiparameter score, rather than simply a surrogate for other end-points such as survival or clinical deterioration.

The PAH patient and caregiver community needs to be cognisant of the developing opportunity to participate in relevant advisory and steering committees in order to advocate for the patients' perspective in clinical trial design. This might be best pursued by patient organisations by advocating for and facilitating patients to serve as steering committee members, patient liaisons or focus group members for study designs, as an outgrowth of US FDA and European Medicines Agency initiatives to promote "patient-focused drug development".

\section{Patient associations}

Recognise and enhance the role of PAH patient organisations/professional organisations

As noted, existing patient organisations (e.g. in the USA, Europe and elsewhere) work as a loose confederation with a similarity of general objectives adapted to their constituencies' specific realities and needs (table 3). Such patient associations have a track record of providing a voice and support for the $\mathrm{PH}$ patient community. Thus, continued development of these organisations should be supported and similar associations should be established in underserved areas. Obstacles to globalisation of $\mathrm{PH}$ patient organisations are significant and include: funding, geographic dispersion of rare disease patients, communication barriers, questions of organisational governance and substantial differences in delivery of medical care. The commonality of objectives and needs of $\mathrm{PH}$ patients suggest that stronger networking for the purposes of educational efforts and sharing of productive strategies should be promoted. An important step forward in this direction was taken in 2017 when the US PHA, SLHP and PHA Europe decide to join forces for the first time in organising the World Pulmonary Hypertension Day, which, in turn rallied many other associations from other parts of the world, including from Canada, Africa, Asia and Australia. Social media can play an increasing role in the future in breaking down geographical barriers and having a unifying function, and other avenues for collaboration should be explored.

Conflict of interest: M.D. McGoon reports personal fees for advisory committee work from United Therapeutics, and personal fees for data monitoring committee work from Pfizer and Acceleron, outside the submitted work. P. Ferrari has nothing to disclose. I. Armstrong has nothing to disclose. M. Denis has nothing to disclose. L.S. Howard reports speaker fees, honoraria for scientific advice and congress/travel support from Actelion and MSD, speaker fees, honoraria for scientific advice, congress/travel support and research grant support from Bayer, and honoraria for scientific advice from GSK, Third Pole, Gossamer, Arena and Endotronix, outside the submitted work. G. Lowe has nothing to disclose. S. Mehta has nothing to disclose. N. Murakami has nothing to disclose. B.A. Wong has nothing to disclose.

\section{References}

1 PHA Europe. The impact of pulmonary arterial hypertension (PAH) on the lives of patients and carers: results from an international survey. 2012. www.phaeurope.org/wp-content/uploads/International-PAH-patient-andCarer-Survey-Report-FINAL1.pdf Date last accessed: June 7, 2018.

2 Guillevin L, Armstrong I, Aldrighetti R, et al. Understanding the impact of pulmonary arterial hypertension on patients' and carers' lives. Eur Respir Rev 2013; 22: 535-542.

3 PHA Online University. Impact of PAH on the lives of patients and caregivers. 2012. www.phaonlineuniv.org/ DiagnosisTreatment/content.cfm?ItemNumber=3417 Date last accessed: June 7, 2018.

4 PHA Canada. The impact of pulmonary hypertension on Canadians. 2013. www.phacanada.ca/en/about-ph/ boi-report Date last accessed: June 7, 2018. 
5 PHA Japan. 3.5 years on average until the start of consultations with a specialist revealed in patient surveys on chronic thromboembolic pulmonary hypertension and pulmonary arterial hypertension. 2013. www.pha-japan.ne. jp/_pdf/medicalspecialist_en.pdf Date last accessed: June 7, 2018.

6 Delcroix M, Howard L. Pulmonary arterial hypertension: the burden of disease and impact on quality of life. Eur Respir Rev 2015; 24: 621-629.

7 Chen H, De Marco T, Kobashigawa EA, et al. Comparison of cardiac and pulmonary-specific quality-of-life measures in pulmonary arterial hypertension. Eur Respir J 2011; 38: 608-616.

8 Chua R, Keogh AM, Byth K, et al. Comparison and validation of three measures of quality of life in patients with pulmonary hypertension. Intern Med J 2006; 36: 705-710.

9 Ware JEJ, Sherbourne CD. The MOS 36-item short-form health survey (SF-36). I. Conceptual framework and item selection. Med Care 1992; 30: 473-483.

10 EuroQol Group. EuroQol - a new facility for the measurement of health-related quality of life. Health Policy 1990; 16: 199-208.

11 Hunt SM, McEwen J. The development of a subjective health indicator. Sociol Health Illn 1980; 2: 231-246.

12 Zigmond AS, Snaith RP. The hospital anxiety and depression scale. Acta Psychiatr Scand 1983; 67: 361-370.

13 McKenna SP, Doughty N, Meads DM, et al. The Cambridge Pulmonary Hypertension Outcome Review (CAMPHOR): a measure of health-related quality of life and quality of life for patients with pulmonary hypertension. Qual Life Res 2006; 15: 103-115.

14 Rector TS, Kubo SH, Cohn JN. Patients' self-assessment of their congestive heart failure. Part 2: content, reliability and validity of a new measure, the Minnesota Living with Heart Failure Questionnaire. Heart Fail 1987; 3: $198-219$

15 Bonner N, Abetz L, Meunier J, et al. Development and validation of the living with pulmonary hypertension questionnaire in pulmonary arterial hypertension patients. Health Qual Life Outcomes 2013; 11: 161.

16 Guyatt GH, Nogradi S, Halcrow S, et al. Development and testing of a new measure of health status for clinical trials in heart failure. J Gen Intern Med 1989; 4: 101-107.

17 Yorke J, Corris P, Gaine S, et al. emPHasis-10: development of a health-related quality of life measure in pulmonary hypertension. Eur Respir J 2013; 43: 1106-1113.

18 McCollister D, Shaffer S, Badesch DB, et al. Development of the Pulmonary Arterial Hypertension-Symptoms and Impact (PAH-SYMPACT) questionnaire: a new patient-reported outcome instrument for PAH. Respir Res 2016; 17: 72 .

19 Lowe B, Grafe K, Ufer C, et al. Anxiety and depression in patients with pulmonary hypertension. Psychosom Med 2004; 66: 831-836.

20 Taichman DB, Shin J, Hud L, et al. Health-related quality of life in patients with pulmonary arterial hypertension. Respir Res 2005; 6: 92.

21 Vanhoof JMM, Delcroix M, Vandevelde E, et al. Emotional symptoms and quality of life in patients with pulmonary arterial hypertension. J Heart Lung Transplant 2014; 33: 800-808.

22 Rival G, Lacasse Y, Martin S, et al. Effect of pulmonary arterial hypertension-specific therapies on health-related quality of life: a systematic review. Chest 2014; 146: 686-708.

23 Barst RJ, Langleben D, Frost A, et al. Sitaxsentan therapy for pulmonary arterial hypertension. Am J Respir Crit Care Med 2004; 169: 441-447.

24 Girgis RE, Frost AE, Hill NS, et al. Selective endothelin A receptor antagonism with sitaxsentan for pulmonary arterial hypertension associated with connective tissue disease. Ann Rheum Dis 2007; 66: 1467-1472.

25 Mychaskiw MA, Hwang L-J, Liu X, et al. The effect of sitaxentan on exercise capacity, hemodynamic function, and health-related quality of life across who functional class in adults with pulmonary arterial hypertension. Am $J$ Respir Crit Care Med 2011; 183: A5887.

26 Galiè N, Olschewski H, Oudiz RJ, et al. Ambrisentan for the treatment of pulmonary arterial hypertension: results of the ambrisentan in pulmonary arterial hypertension, randomized, double-blind, placebo-controlled, multicenter, efficacy (ARIES) study 1 and 2. Circulation 2008; 117: 3010-3019.

27 Galiè N, Rubin LJ, Hoeper MM, et al. Treatment of patients with mildly symptomatic pulmonary arterial hypertension with bosentan (EARLY study): a double-blind, randomised controlled trial. Lancet 2008; 371: 2093-2100.

28 Ghofrani HA, Galiè N, Grimminger F, et al. Riociguat for the treatment of pulmonary arterial hypertension. N Engl J Med 2013; 369: 330-340.

29 Mehta S, Sastry BKS, Souza R, et al. Macitentan improves health-related quality of life for patients with pulmonary arterial hypertension. Chest 2017; 151: 106-118.

30 Pepke-Zaba J, Beardsworth A, Chan M, et al. Tadalafil therapy and health-related quality of life in pulmonary arterial hypertension. Curr Med Res Opin 2009; 25: 2479-2485.

31 Pepke-Zaba J, Gilbert C, Collings L, et al. Sildenafil improves health-related quality of life in patients with pulmonary arterial hypertension. Chest 2008; 133: 183-189.

32 Sastry BK, Narasimhan C, Reddy NK, et al. Clinical efficacy of sildenafil in primary pulmonary hypertension: a randomized, placebo-controlled, double-blind, crossover study. J Am Coll Cardiol 2004; 43: 1149-1153.

33 Barst RJ, McGoon MD, McLaughlin VV, et al. Beraprost therapy for pulmonary arterial hypertension. J Am Coll Cardiol 2003; 41: 2119-2125.

34 Barst RJ, Rubin LJ, Long WA, et al. A comparison of continuous intravenous epoprostenol (prostacyclin) with conventional therapy for primary pulmonary hypertension. N Engl J Med 1996; 334: 296-301.

35 Galiè N, Barbera JA, Frost AE, et al. Initial use of ambrisentan plus tadalafil in pulmonary arterial hypertension. N Engl J Med 2015; 373: 834-844.

36 McLaughlin VV, Benza RL, Rubin LJ, et al. Addition of inhaled treprostinil to oral therapy for pulmonary arterial hypertension: a randomized controlled clinical trial. J Am Coll Cardiol 2010; 55: 1915-1922.

37 Olschewski H, Simonneau G, Galiè N, et al. Inhaled iloprost for severe pulmonary hypertension. $N$ Engl J Med 2002; 347: 322-329.

38 Oudiz R, Schilz RJ, Barst RJ, et al. Treprostinil, a prostacyclin analogue, in pulmonary arterial hypertension associated with connective tissue disease. Chest 2004; 126: 420-427. 
39 Simonneau G, Barst RJ, Galiè N, et al. Continuous subcutaneous infusion of treprostinil, a prostacyclin analogue, in patients with pulmonary arterial hypertension. Am J Respir Crit Care Med 2002; 165: 800-804.

40 Simonneau G, Rubin LJ, Galiè N, et al. Addition of sildenafil to long-term intravenous epoprostenol therapy in patients with pulmonary arterial hypertension: a randomized trial. Ann Intern Med 2008; 149: 521-530.

41 Sitbon O, Channick R, Chin KM, et al. Selexipag for the treatment of pulmonary arterial hypertension. $N$ Engl $J$ Med 2015; 373: 2522-2533.

42 Peacock A, Galiè N, Barbera JA, et al. Initial combination therapy of ambrisentan and tadalafil and quality of life: SF-36 \& CAMPHOR analyses from the AMBITION trial. Am J Respir Crit Care Med 2017; 195 : A6905.

43 Fernandes CJ, Martins BC, Jardim CV, et al. Quality of life as a prognostic marker in pulmonary arterial hypertension. Health Qual Life Outcomes 2014; 12: 130.

44 Batal O, Khatib OF, Bair N, et al. Sleep quality, depression, and quality of life in patients with pulmonary hypertension. Lung 2011; 189: 141-149.

45 Galiè N, Humbert M, Vachiery JL, et al. 2015 ESC/ERS Guidelines for the diagnosis and treatment of pulmonary hypertension. Eur Respir J 2015; 46: 903-975.

46 Arena R, Cahalin LP, Borghi-Silva A, et al. The effect of exercise training on the pulmonary arterial system in patients with pulmonary hypertension. Prog Cardiovasc Dis 2015; 57: 480-488.

47 Fenstad ER, Shanafelt TD, Sloan JA, et al. Physician attitudes toward palliative care for patients with pulmonary arterial hypertension: results of a cross-sectional survey. Pulm Circ 2014; 4: 504-510.

48 Buys R, Avila A, Cornelissen VA. Exercise training improves physical fitness in patients with pulmonary arterial hypertension: a systematic review and meta-analysis of controlled trials. BMC Pulm Med 2015; 15: 40.

49 Swetz KM, Shanafelt TD, Drozdowicz LB, et al. Symptom burden, quality of life, and attitudes toward palliative care in patients with pulmonary arterial hypertension: results from a cross-sectional patient survey. J Heart Lung Transplant 2012; 31: 1102-1108.

50 Ivarsson B, Radegran G, Hesselstrand R, et al. Coping, social support and information in patients with pulmonary arterial hypertension or chronic thromboembolic pulmonary hypertension: a 2-year retrospective cohort study. SAGE Open Med 2018; 6: 2050312117749159.

51 Von Visger TT, Kuntz KK, Phillips GS, et al. Quality of life and psychological symptoms in patients with pulmonary hypertension. Heart Lung 2018; 47: 115-121.

52 Badesch DB, Abman SH, Simonneau G, et al. Medical therapy for pulmonary arterial hypertension: updated ACCP evidence-based clinical practice guidelines. Chest 2007; 131: 1917-1928.

53 Galiè N, Hoeper MM, Humbert M, et al. Guidelines for the diagnosis and treatment of pulmonary hypertension. Eur Respir J 2009; 34: 1219-1263.

54 Taichman DB, Ornelas J, Chung L, et al. Pharmacologic therapy for pulmonary arterial hypertension in adults: CHEST guideline and expert panel report. Chest 2014; 146: 449-475.

55 Graarup J, Ferrari P, Howard LS. Patient engagement and self-management in pulmonary arterial hypertension. Eur Respir Rev 2016; 25: 399-407.

56 Charon R. Narrative medicine: a model for empathy, reflection, profession, and trust. JAMA 2001; 286: 1897-1902.

57 Charon R, DasGupta S, Hermann N, et al. The Principles and Practice of Narrative Medicine. New York, Oxford University Press, 2017.

58 Mehl-Madrona L. Narrative Medicine: The Use of History and Story in the Healing Process. Rochester, Bear \& Company, 2007.

59 Greenhalgh T, Hurwitz B. Narrative based medicine: why study narrative? BMJ 1999; 318: 48-50.

60 Marini MG. Narrative Medicine: Bridging the Gap between Evidence-Based Care and Medical Humanities. Cham, Springer, 2016.

61 Howard LS, Ferrari P, Mehta S. Physicians' and patients' expectations of therapies for pulmonary arterial hypertension: where do they meet? Eur Respir Rev 2014; 23: 458-468.

62 Kunneman M, Montori VM, Castaneda-Guarderas A, et al. What is shared decision making? (and what it is not). Acad Emerg Med 2016; 23: 1320-1324.

63 Kavalieratos D, Gelfman LP, Tycon LE, et al. Palliative care in heart failure: rationale, evidence, and future priorities. J Am Coll Cardiol 2017; 70: 1919-1930.

64 Centers for Medicare \& Medicaid Services. Medicare and Medicaid programs: hospice conditions of participation, Final Rule. Fed Regist 2008; 73: 32087-32220.

65 Chen H, Taichman DB, Doyle RL. Health-related quality of life and patient-reported outcomes in pulmonary arterial hypertension. Proc Am Thorac Soc 2008; 5: 623-630.

66 Peloquin J, Robichaud-Ekstrand S, Pepin J. Quality of life perception by women suffering from stage III or IV primary pulmonary hypertension and receiving prostacyclin treatment. Can J Nurs Res 1998; 30: 113-136.

67 Rubenfire M, Lippo G, Bodini BD, et al. Evaluating health-related quality of life, work ability, and disability in pulmonary arterial hypertension. Chest 2009; 136: 597-603.

68 Shafazand S, Goldstein MK, Doyle RL, et al. Health-related quality of life in patients with pulmonary arterial hypertension. Chest 2004; 126: 1452-1459.

69 Zlupko M, Harhay MO, Gallop R, et al. Evaluation of disease-specific health-related quality of life in patients with pulmonary arterial hypertension. Respir Med 2008; 102: 1431-1438.

70 Matura LA, McDonough A, Carroll DL. Symptom prevalence, symptom severity, and health-related quality of life among young, middle, and older adults with pulmonary arterial hypertension. Am J Hosp Palliat Care 2014; 33: $214-221$.

71 Ivarsson B, Radegran G, Hesselstrand R, et al. Information, social support and coping in patients with pulmonary arterial hypertension or chronic thromboembolic pulmonary hypertension - a nationwide population-based study. Patient Educ Couns 2017; 100: 936-942.

72 Brown LM, Chen H, Halpern S, et al. Delay in recognition of pulmonary arterial hypertension: factors identified from the REVEAL Registry. Chest 2011; 140: 19-26.

73 Deano RC, Glassner-Kolmin C, Rubenfire M, et al. Referral of patients with pulmonary hypertension diagnoses to tertiary pulmonary hypertension centers: the multicenter RePHerral Study. JAMA Intern Med 2013; 173: 887-893.

74 Simonneau G, Galiè N. Updates in pulmonary hypertension. I Am Coll Cardiol 2013; 62: D1-D128. 
75 Carman KL, Dardess P, Maurer M, et al. Patient and family engagement: a framework for understanding the elements and developing interventions and policies. Health Aff 2013; 32: 223-231.

76 Coulter A, Ellins J. Effectiveness of strategies for informing, educating, and involving patients. BMJ 2007; 335: $24-27$.

77 US Food and Drug Administration. Guidance for Industry. Patient-reported outcome measures: use in medical product development to support labeling claims. 2009. www.fda.gov/downloads/Drugs/Guidances/UCM193282.pdf Date last accessed: June 7, 2018

78 McLaughlin VV, Badesch DB, Delcroix M, et al. End points and clinical trial design in pulmonary arterial hypertension. J Am Coll Cardiol 2009; 54: S97-S107.

79 Gomberg-Maitland M, Bull TM, Saggar R, et al. New trial designs and potential therapies for pulmonary artery hypertension. J Am Coll Cardiol 2013; 62: D82-D91.

80 Perdetto EM, Burke L, Oehrlein EM, et al. Patient-focused drug development: a new direction for collaboration. Med Care 2015; 53: 9-17.

81 US Food and Drug Administration. CDER patient focused drug development. 2018. https://collaboration.fda.gov/ p36001255/?launcher=false\&fcsContent=true\&pbMode=normal Date last accessed: October 29, 2018.

82 US Food and Drug Administration. The voice of the patient: pulmonary arterial hypertension. 2014. www.fda.gov/ downloads/ForIndustry/UserFees/PrescriptionDrugUserFee/UCM429382.pdf Date last accessed: June 7, 2018. 